LUCIANA SANGUINETTI* Facultad de Derecho de la Universidad de Montevideo (UM), Uruguay. Isanguinetti@correo.um.edu.uy ORCID iD: https://orcid.org/0000-0002-1599-3776

Recibido: 30/04/2021 - Aceptado: 25/05/2021

Para citar este artículo / To reference this article / Para citar este artigo Sanguinetti, L. (202I). La desheredación como forma de exlusión sucesoria. Revista de Derecho, 20(39) 221-243. https://doi.org/I 0.47274/DERUM/39.9

\title{
La desheredación como forma de exclusión sucesoria
}

Resumen: La desheredación es una forma de exclusión sucesoria que recoge nuestro ordenamiento jurídico. En el siguiente trabajo el lector se encontrará con un detallado análisis conceptual y práctico donde, además de una aproximación conceptual del instituto en estudio, así como de sus requisitos de validez, funcionamiento y causas de procedencia; propongo replantearnos una flexibilización de la normativa que nos gobierna a los efectos de garantizarle mayor protagonismo a la libertad para testar del causante.

Palabras clave: Desheredación; Exclusión sucesoria; Validez de la desheredación; Procedencia de la desheredación; Prueba de la desheredación.

* Procuradora por Universidad de Montevideo (Uruguay). Estudiante de abogacía en la Universidad de Montevideo (Uruguay). 


\title{
The desinheritance as a form of succession exclusion
}

\begin{abstract}
The disinheritance is a form of succession exclusion that our legal system includes. In the following work the reader will find a detailed conceptual and practical analysis where, in addition to a conceptual approach to the institute under study, as well as its requirements for validity, operation and causes of origin; I propose to rethink a flexibilization of the regulations that govern us in order to ensure greater prominence to the freedom to test by the deceased.
\end{abstract}

Key Words: Disinheritance; Succession exclusion; Disinheritance validity; Origin of the disinheritance; Proof of disinheritance.

\section{A deserdação como forma de exclusão sucessória}

Resumo: Adeserdação é uma forma de exclusão sucessória incluída em nosso ordenamento jurídico. No seguinte trabalho o leitor encontrará uma detalhada análise conceitual e prática, além de uma aproximação conceitual do instituto em estudo, bem como seus requisitos de validade, funcionamento e causas de origem; proponho repensar a flexibilização das normas que nos regem, para efeitos de garantir maior destaque à liberdade para testar do falecido.

Palavras-chave: Deserdação; Exclusão Sucessória; Validade da deserdação, Procedência da deserdação; Prova da deserdação. 


\section{Introducción}

En nuestro ordenamiento jurídico, el hecho de que una persona sea llamada a suceder no se considera un acontecimiento determinante ni concluyente, puesto que existen numerosos casos en los cuales se ha determinado que dicho sujeto sea excluido de la sucesión, por haber incurrido en comportamientos que permiten al de cuius o a los tribunales de justicia, privarlo de su condición de sucesor. (Howard, 2019)

La desheredación es una hipótesis de exclusión sucesoria prevista en el art. 896 del Código Civil Uruguayo (en adelante "C.C.U”). Se define como "una disposición testamentaria, por la cual se priva de su legítima a aquel sujeto que es considerado heredero forzoso" (Código Civil Uruguayo. Ley 16.603 de 1994. 19 de octubre de 1994. Uruguay.)

Se trata de un instituto que opera a través de una disposición testamentaria, alcanzando únicamente a los legitimarios, es decir, a aquellos sujetos que se ven favorecidos con un beneficio exclusivo conocido como las legítimas.

Nuestra normativa interna se encarga de prever quiénes serán los legitimarios; dejando así un ámbito muy acotado de elección para que el causante pueda elegir libremente quienes serán los beneficiarios. Si bien, a través de la figura en estudio, recobra mayor protagonismo la libertad del testador para disponer, no es tan simple la operatividad del instituto en análisis, puesto que las causas para su procedencia son taxativas, exigiéndose una intensa carga probatoria, cuando la desheredación es resistida por parte de quien es excluido.

Para que tenga lugar la desheredación se requiere que el causante recurra al testamento; la finalidad de ésta es privar al heredero forzoso de la legitima que le corresponde. Se trata de un derecho del testador de privar a su heredero forzoso de aquella asignación forzosa a la que tiene derecho en calidad de tal. Si testador quisiera excluir de la herencia a otro heredero que no es legitimario, podría hacerlo también; pero ya no se trataría de una desheredación sino de una exclusión de su calidad de heredero, no siendo necesario para esta última que se cumplan los requisitos previstos para la desheredación (Rivero de Arhancet, 2001).

\section{Concepto}

Conforme al art. 896 del C.C.U, la desheredación es una disposición testamentaria por la cual se priva o excluye de su legítima a los herederos forzosos. El instituto alcanza únicamente a los legitimarios.

El art. 884 del C.C.U dispone lo siguiente: “Llámase legítima la parte de bienes que la Ley asigna a cierta clase de herederos, independientemente de la voluntad del testador y de que éste no puede privarlos, sin causa justa y probada de desheredación. Los herederos que tienen legítima se llaman legitimarios o herederos forzosos" (Código Civil Uruguayo. Ley 16.603 de 1994. 19 de octubre de 1994. Uruguay).

De acuerdo con el art. 885 del C.C.U, tienen legítima o, lo que es lo mismo, son legitimarios " $1^{\circ}$.- Los hijos legítimos, personalmente o representados por sus 
descendientes legítimos o naturales. $2^{\circ}$.- Los hijos naturales, reconocidos o declarados tales, personalmente o representados por su descendencia legítima o natural. $3^{\circ}$.- Los ascendientes legítimos (Código Civil Uruguayo. Ley 16.603 de 1994. 19 de octubre de 1994. Uruguay).

Es concluyente que la desheredación no opera respecto de todas las asignaciones forzosas, sino únicamente respecto de las legítimas en función de que solo tiene virtualidad a fin de excluir a los llamados merced a esta situación. Como prescribe el art. 870 del C.C.U, las asignaciones forzosas son aquellas que el testador está obligado a realizar y que, en caso de que no las haga, se suplen, aun en perjuicio de disposiciones testamentarias expresas.

La libertad del causante para testar cede ante la procedencia del articulo antes citado; el de cuius se encuentra obligado a cumplir con tales asignaciones forzosas, y en caso de que no lo haga, su voluntad se ve colmada por el imperio de la ley.

Del lado del causante, la legitima es una verdadera limitación al derecho de testar, puesto que el derecho a la misma encuentra sus fundamentos en los vínculos de familia. Por dicho motivo, la afectación del beneficio previsto en la ley debe tener lugar únicamente invocando alguna de las causas preceptuadas taxativamente en la normativa, no extensibles analógicamente.

Ciertamente, la figura en estudio no solamente se encuentra afiliada al principio de legalidad (puesto que las causas que deben invocarse son las recogidas por la ley) sino que, además, se adhiere al mismo el principio de tipicidad. Dado el carácter sancionatorio que luce la figura, la misma debe ajustarse a los principios antes citados, propio de las regulaciones que imponen sanciones a las conductas reprobables.

Ahora bien, cuando la solidaridad intergeneracional que caracteriza a las legítimas ha desaparecido como consecuencia de un comportamiento reprobable del legitimario, previsto en la ley, la privación de este derecho es lícita.

No sería racional obligar a un testador a favorecer a quien por su conducta reparable no se ha hecho digno de recibir el beneficio, puesto que si la legítima se funda en los deberes de asistencia y afecto del causante hacia el legitimario, la desheredación significa la dispensa que la Ley confiere al testador de seguir vinculado por tal deber, ante la concurrencia de una causa grave y legalmente reconocida (Howard, 2019, p. 557).

Por el principio de la intangibilidad de las legítimas, los legitimarios tienen derecho a recibir la cuota parte que legalmente les corresponde. Si bien, la misma no debe ser afectada ni cuantitativa ni cualitativamente; se entiende que quien vulnera los vínculos de familia por la operatividad de alguna de las conductas previstas en la ley, no puede ser beneficiado por una institución jurídica que encuentra, justamente, sus fundamentos en los vínculos de familia.

El instituto de la desheredación cuenta con dos limitaciones normativas para poder operar:

En primer lugar, el art. 896 del C.C.U exige, al definirla, una manifestación de la voluntad expresa; ya que la desheredación no puede presumirse, ni deducirse de los negocios inter vivos del causante, ni ser tácita. 
Una segunda limitación, viene dada por el art. 897 del C.C.U. Preceptúa los requisitos que, en su totalidad, deben reunirse para que la desheredación no sea nula o, lo que es lo mismo, no sea dejada sin efecto para el caso de que sea objetada.

\section{Requisitos de validez}

Para que la figura en estudio no sea impugnable es fundamental que se cumplan los requisitos de validez previstos la ley; de lo contrario, si los mismos no confluyen en su totalidad, la desheredación será declarada nula.

Tal como se desprende del art. 897 del C.C.U, el incumplimiento de cualquiera de los requisitos acarrea la falta de validez de la desheredación (Rivero de Arhancet, 2001).

Para que valga la desheredación se requiere:

\subsection{Que se haga en testamento válido.}

El testamento es un instrumento de planificación sucesoria por el cual el disponente encauza el destino de sus bienes, de conformidad con su autonomía privada, para cuando haya cesado de vivir; corrigiendo con su voluntad la distribución hereditaria que se lleva a cabo por parte de la ley (Howard, 2020).

Se trata de un negocio jurídico, que debe otorgarse con discernimiento, intención y libertad por parte del testador, puesto que sería nulo en caso de que se ausente su libre voluntad, y anulable en caso de que dicha voluntad exista, pero este viciada por error, violencia o dolo.

Es un acto de disposición de bienes; directa, en caso de instituir herederos o legatarios $\mathrm{o}$, indirecta, en caso de prever la desheredación de un legitimario.

No solamente debe tratarse de un testamento valido; se requiere además que el mismo no se haya revocado. Al tratarse de un acto esencialmente revocable, la posibilidad de hacerlo por la sola voluntad del testador existe hasta su muerte, como lo prevé el art. 998 del C.C.U. Si el testador desheredó a un legitimario, y luego revoca dicho testamento, más allá de que no mencione la disposición en cuestión, la desheredación quedará sin efecto puesto que cae el testamento en la que fue dispuesta la misma (Howard, 2019).

\subsection{Que sea hecha pura y simplemente y del total de la legitima.}

La desheredación no puede sujetarse a un plazo, ni condición, y debe alcanzar la totalidad de la legítima.

El instituto es un modo de exclusión de la legitima; no lo es de otros beneficios que pueda recibir el sucesor. La ley es clara al expresar que la afectación es sobre la legítima, no sobre otros beneficios. Nada impide que el sucesor se viera beneficiado de otra manera, como por ejemplo con un legado, a pesar de haber perdido su legítima.

La desheredación debe que ser pura y simple. No debe estar sometidas a condiciones ni plazos. Esto no impide que, en caso de que el testador no tenga certeza absoluta de la existencia de la causa, condicione la desheredación a la probanza de ésta con posterioridad; en verdad no se está condicionando la concurrencia o no de la causa, sino 
solamente de su prueba. No es lo mismo, por ejemplo, disponer "desheredo a mi hijo X si intentara matarme", a decir, "revoco la desheredación de mi hijo X si se probara que se ha arrepentido de haber intentado matarme" (Howard, 2019).

Tampoco sería admisible desheredar a futuro, previendo la procedencia de la desheredación para la eventual hipótesis de que en el futuro el legitimario incurriera en alguna de las causales descriptas por la ley.

El fundamento de que la desheredación no pueda someterse a ningún plazo ni condición viene dado porque, al tratarse de una disposición testamentaria, se origina plenamente en las causales previstas en la ley. Se debe vincular la desheredación a una causal que la motive; si la misma no existe al momento de incluir la disposición testamentaria, no habría desheredación.

De lo contrario, se afectarían los derechos que la ley protege y reconoce a los legitimarios, puesto que sería incoherente e incongruente prever la desheredación (con todas las consecuencias que ello apareja) y esperar a que la casual ocurra. Solamente los hechos previstos en la ley tienen aptitud o significación jurídica para conducir a la desheredación; si esos hechos no se configuran, no operaría la misma.

\subsection{Que se designe al desheredado por su nombre y se exprese clara y específicamente la causa de la desheredación.}

Este ordinal refiere a dos requisitos diferentes: por un lado, a la designación del desheredado, y por otro, a la causa de la desheredación.

En lo que respecta a la designación del desheredado, se lo debe indicar precisamente a través de su nombre, más allá de que no existan dudas acerca de su identificación, o que se tenga certeza quién es el sujeto.

La ley es exige el nombre del desheredado, excluyendo así el manejo de un apodo o seudónimo; pero no exige el nombre y apellido del sujeto; siendo suficiente con el nombre de pila de éste. Sin embargo, más allá de que no se puedan pretender requisitos que la propia ley no prevé, es de entenderse que la designación tiene que ser clara, inequívoca e indudable.

En lo que respecta al requisito de la expresión de la causa, se debe tener en cuenta que la especificidad de la que habla la ley, más que a una referencia puntual de alguna de las causas tipificadas, debe entenderse en sentido amplio, determinando los hechos u eventos que llevan al testador a imponer la sanción civil. Si las palabras del testador son claras para reflejar que los hechos ocurridos ingresan dentro de la causal prevista; es suficiente. Pero, más aún, ella (o ellas, puesto que nada impide que coexistan varias causas de desheredación) debe formar parte del elenco de causas que están previstas taxativamente en la norma, debiendo ser probada.

Esto último por cuanto la naturaleza de la figura es de una típica sanción civil; debe ajustarse al principio de tipicidad, propio de las regulaciones que imponen sanciones a las conductas reprobables; donde su acreditación y probanza forma parte de su invocación.

Por aplicación de los arts. 899 y 900 del C.C.U, solamente las conductas y hechos contenidos expresamente en la ley tienen la suficiencia para conducir a la desheredación. Los demás acontecimientos que puedan ocurrir, aun siendo perjudiciales, denigrantes, 
inmorales y deshonestos para con el testador, carecen de aptitud para lograr el fin perseguido por la norma por no estar incluidos en ella.

\subsection{Si el desheredado es un hijo o descendiente, se requiere, además, que haya cumplido dieciocho años.}

Para ser desheredado se requiere que el legitimario haya alcanzado la mayoría de edad. Sin embargo, el Código omite indicar en qué momento el legitimario debe tener esa edad, o, lo que es lo mismo, cuando debe mirarse esa exigencia de edad. Doctrinariamente se ha entendido que la capacidad para incurrir en las causales de desheredación debe observarse en el momento en que se producen los hechos que la motivan. (Howard, 2019).

\section{Causas de desheredación}

Las causas de desheredación deben ser analizadas restrictivamente, no debiendo ser extendidas por analogía, ya que suponen la limitación de un derecho: las legítimas.

Cobra especial relevancia el principio de intangibilidad de las legítimas; esta última podría verse afectada únicamente por las causales de desheredación que la ley prevé. Es así como el art. 898 del C.C.U nos indica que "la causa en que se funda la desheredación deberá ser alguna de las señaladas expresamente en la ley." (Código Civil Uruguayo. Ley 16.603 de 1994. 19 de octubre de 1994. Uruguay.)

En orden a lo que acaba de decirse, como la figura denota total característica sancionatoria, debe ajustarse al principio de legalidad y tipicidad. Nadie puede ser sancionado sin que exista una ley que tipifique, para un comportamiento notoriamente reprobable, un castigo.

Según el art. 899 del C.C.U, "todas las causas de indignidad para suceder (art. 842 C.C.U) lo son también respectivamente de desheredación”. (Código Civil Uruguayo. Ley 16.603 de 1994. 19 de octubre de 1994. Uruguay.)

Acompañando este precepto, el art. 900 del C.C.U detalla cuáles serían, además de las previstas por el art. 842, justas causas de desheredación de los hijos y descendientes; mientras que, el art. 901 del C.C.U, prescribe aquellas que se podrían invocar para que el padre y la madre puedan ser desheredados por sus hijos.

Entonces, de acuerdo con los arts. 899 a 901 del C.C.U, se advierte lo siguiente: existen tres grupos de causas: 1) todas aquellas que producen la indignidad 2) las que afectan a los hijos y descendientes 3) las que tienen por finalidad excluir a los ascendientes matrimoniales.

\subsection{Causas de la indignidad aplicables a la desheredación}

Si bien, para la operatividad de la desheredación, existe una remisión expresa a las causas de la indignidad; la realidad es que no todas las que se encuentran previstas para esta última figura son igualmente aplicables a la desheredación.

A la par de lo dicho, algunas causales de la indignidad operan una vez que el sujeto ha fallecido, lo cual no es coherente ni coincidente con el instituto en estudio, puesto 
que la desheredación es una disposición testamentaria, y para configurarse como tal requiere de la voluntad del causante (Howard, 2019).

Las causales previstas en el art. 899 del C.C.U, son las siguientes:

\subsection{1. "El condenado en juicio por homicidio intencional o tentativa del mismo contra la persona de cuya herencia se trata, contra el cónyuge y contra los descendientes del mismo.}

Si alguno de los herederos forzosos incurre en esta causal de indignidad, pierde también su legítima." (Código Civil Uruguayo. Ley 16.603 de 1994. 19 de octubre de 1994. Uruguay).

Esta causal tiene un referencia subjetiva y objetiva.

En cuanto a la referencia subjetiva, quien haya sido condenado por un homicidio intencional o tentativa del mismo, debe haber desarrollado esa conducta contra el sujeto de cuya herencia se trata, contra el cónyuge y contra los descendientes del mismo.

Se trata de una causal de gran componente ético, moral, y de gran reprobación judicial, puesto que el beneficiario privó o intentó privar de su vida al causante; es decir, el sujeto de quien pretende obtener un beneficio, como lo es la legitima.

Las víctimas de la conducta delictiva, además de ser la persona de quien se hereda, alcanza a su cónyuge o sus descendientes ( $\sin$ limitación de grado ni parentesco impuesto por la ley, ni distinción de la filiación- si es matrimonial o extramatrimonial-)

En cuanto a la referencia objetiva, se requiere una sentencia penal condenatoria ejecutoriada por homicidio intencional o tentativa de homicidio, configurándose la causal de indignidad solamente cuando exista sentencia de condena.

Vemos que la ley no solo considera realmente reprobable la conducta delictiva de dar muerte a un sujeto, sino también la tentativa de cometer esa conducta. Castiga de la misma manera la intención de dar muerte a una persona, y la consumación de la conducta delictual. La norma abarca un estadio previo a la efectiva consumación del delito. No es admisible que, quien tuviera la intención de quitarle la vida al testador, luego se beneficie de los derechos sucesorios que la ley le concede.

Como bien lo determina la norma, se requiere intención. No se encuentra englobada la conducta culposa; la norma no lo prevé. Para que una conducta se castigue a título de culpa debe estar expresamente prevista en la ley, ya que el hecho culpable solamente es punible en los casos determinados por ley, tal como deriva del art. 19 del Código Penal Uruguayo.

Por lo tanto, no se considerará configurada la causal en casos de homicidio culposo, homicidios no imputables (como los ocurridos en estado de embriaguez o demencia, etc.), puesto que la norma es clara al exigir un evento que debe ser querido e incluso previsto.

Como lo adelantábamos, la aplicación de esta causal en el campo de la desheredación debe hacerse sopesando las características del instituto en estudio, puesto que operaría solamente en caso de que haya existido condena ejecutoriada de tentativa de homicidio para con la persona de quien se hereda, así como condena ejecutoriada de homicidio o tentativa del mismo contra la persona del cónyuge o descendientes del testador. 
4.1.2. "El heredero mayor de edad que, sabedor de la muerte violenta del difunto, no la denuncia dentro de sesenta dias a la justicia cuando esta no ha procedido ya de oficio sobre ella.

Si los homicidas fueren ascendientes o descendientes o hermanos del heredero o cónyuge cesara en éste la obligación de denunciar" (Código Civil Uruguayo. Ley 16.603 de 1994. 19 de octubre de 1994. Uruguay).

No podría operar dicha causal en el campo de desheredación por los siguientes motivos:

Primero, porque esta causal tiene como presupuesto la intervención de oficio por parte de la justicia. Solamente en caso de que esta última no haya intervenido de oficio, podría operar la causal; pero aún en este último caso existen ciertas limitaciones: que se trate de un heredero mayor de edad, sabedor de la muerte violenta del difunto, y no haberla denunciado dentro de los sesenta días a la justicia. Por obvias razones no podría operar como causal de desheredación; para que esta última proceda se requiere de la voluntad del testador; no existente en caso de que el mismo haya fallecido.

En segundo lugar, incluso no habiendo cumplido con la obligación de denunciar la muerte del causante; el sujeto tampoco podría ser privado de su herencia en caso de que el homicida sea ascendiente, descendiente, hermano o cónyuge del heredero legitimario.

\subsection{3. "El que voluntariamente acusó o denunció al difunto de un delito capital” (Código Civil Uruguayo. Ley 16.603 de 1994. 19 de octubre de 1994. Uruguay).}

La ley habla de difunto, evidentemente se refiere al testador fallecido; cronológicamente no sería posible invocar esta causal para desheredar al beneficiario, porque la desheredación es una disposición testamentaria, y como tal requiere de la voluntad del testador.

El delito capital es aquel que conduce a la pena de muerte. El precepto no recibe aplicación en el ordenamiento jurídico uruguayo ya que se abolió la pena de muerte.

Se considera legalmente inadmisible entender que "delito capital" se refiere a "delito grave" puesto que la ley refiere al delito castigable con pena de muerte, no siendo aplicable esta última en nuestro ordenamiento jurídico.

\subsection{4 " El pariente que, sabiendo ser heredero presuntivo del difunto, y hallándose este demente y abandonado, no cuida de recogerle o hacerle recoger en un establecimiento público" (Código Civil Uruguayo. Ley 16.603 de 1994. 19 de octubre de 1994. Uruguay).}

Claramente la causal operaria en caso de que el sujeto víctima de los hechos deje atrás su estado de demencia y teste excluyendo al legitimario que lo abandonó en las condiciones que el artículo prescribe. 
4.1.5. "El que para heredar estorbó, por fuerza o fraude, que el difunto hiciera testamento o revocara el ya hecho o sustrajo éste o forzó al difunto para testar" (Código Civil Uruguayo. Ley 16.603 de 1994. 19 de octubre de 1994. Uruguay).

Se trata de una causal vinculada con la obstrucción de la libertad para testar. Las conductas que quedarían comprendidas en esta causal son las siguientes (Howard, 2019):

a. estorbar con fuerza o fraude para que el difunto hiciera testamento. Estorbar debe ser entendido con la idea de obstaculizar o dificultar la posibilidad de testar, ya sea por fuerza (tanto por la fuerza física, así como por amenazas que inspiren al testador un temor insuperable), o por fraude (quedando comprendidas las maquinaciones directas o positivas), ya que para estorbar se requiere una conducta directa o activa.

b. utilizar fuerza o fraude para lograr que se revoque un testamento ya hecho. A diferencia del caso anterior, la fuerza y el fraude se utilizan para revocar un testamento que ya se otorgó.

c. sustraer el testamento hecho por el testador. Se trata de una hipótesis que solamente procedería respecto de testamentos que son solemnes cerrados y menos solemnes o especiales.

d. forzar al difunto a testar. Refiriéndose únicamente a la fuerza con el alcance que vimos, pero no al fraude. El testamento sería nulo, por aplicación del art. 789 del C.C.U.

\subsection{Causales que afectan a los hijos y descendientes}

4.2.1. "Haber maltratado de obra o injuriado gravemente la palabra al padre o ascendiente que le deshereda" (Código Civil Uruguayo. Ley 16.603 de 1994. 19 de octubre de 1994. Uruguay).

En la actualidad, se ha tendido a la flexibilización del concepto de maltrato de obra, de tal forma que se han incluido daños y maltratos psicológicos que los hijos provocan a sus padres, incluso no existiendo de por medio violencia física. En la medida en que dichos comportamientos generan un sufrimiento y padecimiento notorio se verían alcanzados por la disposición en estudio. Nada obsta a que los maltratos psicológicos sean notoriamente mayores que el maltrato físico, puesto que pueden causar un gran menoscabo y deterioro a la salud mental del testador mayor que una dolencia corporal.

Dicho comportamiento notoriamente infringe lo previsto por el art. 256 del C.C.U, el cual dispone que "los hijos, cualquiera que sea su estado, edad, y condición, deben honrar y respetar a su padre y a su madre" (Código Civil Uruguayo. Ley 16.603 de 1994. 19 de octubre de 1994. Uruguay).

Las conductas desarrolladas por el legitimario no necesariamente tienen que reputarse de ilícitas; alcanza con que en el entorno afectivo se califiquen como inmorales, indecentes o indecorosas. Lo dicho por cuanto el análisis no recae necesariamente en la conducta en si misma que desenvuelve el legitimario, sino en el sufrimiento, menoscabo, dolor que genera para el testador. 
Ninguna actividad ilegal lleva a cabo el hijo que interna a su padre en un establecimiento geriátrico y ninguna obligación le impone el ordenamiento jurídico de concurrir a visitarlo. Sin embargo, la omisión a este respecto por parte del hijo que produce un daño psicológico a su ascendiente queda comprendida en la noción de maltrato que recoge la disposición. (Howard, 2019, p.584).

El estudio y la prueba de esta causal debe ser enfocada desde una perspectiva objetiva. Es decir, aun existiendo una ofensa, injuria o agravio para con el testador, debe ser analizado objetivamente; la conducta en si misma debe ser agraviante e injuriante.

\subsection{2. "Haberle negado los alimentos, sin motivo legítimo" (Código Civil Uruguayo. Ley 16.603 de 1994. 19 de octubre de 1994. Uruguay).}

El art. 121 del C.C.U, indica: "Bajo la denominación de alimentos se comprende, no solo la casa y la comida, sino el vestido, el calzado, las medicinas y salarios de los médicos y asistentes, en caso de enfermedad.

Se comprende también la educación, cuando el alimentario es menor de veintiún años" (Código Civil Uruguayo. Ley 16.603 de 1994. 19 de octubre de 1994. Uruguay)

Según el artículo citado y el art. 46 del Código de la Niñez y de la Adolescencia (en adelante, C.N.A) el concepto jurídico de alimentos disfruta de un contenido más amplio del que se confiere vulgarmente, ya que incluye comida, casa, vestido, calzado, medicinas, honorarios médicos, etc. El legislador se apartó del sentido natural y obvio de la palabra, para darle un significado especial, de modo que se incluyen también otros rubros que colman diversos requerimientos de la condición humana, además de los alimentos que permiten satisfacer las necesidades naturales del hombre. (Howard, 2016).

Para la operatividad de esta causal es necesario que se configuren los requisitos que la ley prescribe para el nacimiento de la obligación alimentaria: un título que permita exigirlos; las necesidades del beneficiario y las posibilidades de quien debe sufragarlos.

Es así como el art 122 del C.C.U establece que "los alimentos han de ser proporcionados al caudal de quien los da y a las necesidades de quien los recibe" (Código Civil Uruguayo. Ley 16.603 de 1994. 19 de octubre de 1994. Uruguay).

Se trata de una causal que encuentra su contracara en el art. 900 numeral 1 del C.C.U.

En el ámbito de las relaciones paternofiliales, la presente causal encuentra su fundamento en el incumplimiento de las obligaciones que tienen los hijos para con sus padres. Una de ellas es la prestación de alimentos; se trata de una obligación de carácter reciproca entre padres e hijos.

El art. 118 del C.C.U, nos indica que "la obligación de alimentar es reciproca entre los ascendientes y descendientes"; mientras que el art. 279 establece que "la acción de reclamar alimentos es reciproca entre padres e hijos naturales y tendrá lugar siempre que unos u otros se hallaren en circunstancias de no poder proveer a sus necesidades" (Código Civil Uruguayo. Ley 16.603 de 1994. 19 de octubre de 1994. Uruguay). 


\subsection{3. "Haber sido declarado por sentencia pasada en autoridad de cosa juzgada, culpable de un delito y condenado como tal a la pena de cinco años de penitenciaría o a otra pena de mayor gravedad" (Código Civil Uruguayo. Ley 16.603 de 1994. 19 de octubre de 1994. Uruguay).}

Muy pocos ordenamientos jurídicos han incluido entre sus disposiciones esta causal; probablemente sea porque no se trata de un comportamiento delictivo que tenga como víctima al testador, a sus parientes, o familiares.

Es una disposición normativa que no se encuentra ajustada a la realidad que actualmente se vive $y$, seguramente, forme parte del grupo de disposiciones que habría que replantearse modificar. No se comprende la inclusión de una causal de estas características, puesto que en sí misma no debería verse como un impedimento para obtener el beneficio que la ley les asigna a los legitimarios.

Sin perjuicio de lo dicho, el fundamento de haber incluido esta causal tiene una doble vertiente: por un lado, el hecho de haber sido sancionado con una pena de cinco años de penitenciaría o de mayor gravedad arroja deshonra sobre la familia y, en segundo lugar, porque hace presumir que quien comete este tipo de conductas en realidad no siente afecto por sus ascendientes, porque si así fuera no la habría cometido (Howard, 2019).

\subsection{Causales de desheredación de los ascendientes matrimoniales} en el Código, arts. 284 y stes.” (Código Civil Uruguayo. Ley 16.603 de 1994. 19 de octubre de 1994. Uruguay).

La patria potestad supone un conjunto de derechos y obligaciones que tienen los padres para con la persona y bienes de sus hijos menores. Cuando la conducta que desarrollan los padres los hace indignos de su misión de tales; o cuando se dan ciertos hechos que manifiestan que los padres no están en condiciones de afrontar las exigencias que demanda el correcto funcionamiento de la patria potestad; en tales casos la ley se encarga de enumerar conductas que suponen la perdida de la patria potestad en protección de los hijos menores (Cestau, 1999).

Los comportamientos que precisa nuestra normativa suponen una afectación a la persona de los hijos menores. Coherente es la desheredación de los padres por los hijos cuando los primeros emplean conductas que atentan contra los derechos y la protección integral de los segundos.

La normativa prescribe que el padre y la madre pueden ser desheredados con arreglo a esta causal; la cual debe ser analizada de manera estricta, y vista únicamente desde la perspectiva de quien deshereda. Es decir, las causas para desheredar son personales, por lo tanto, solo podría desheredar aquel que fue víctima de los hechos; pero no podría desheredar un hijo a su padre, porque este último haya perdido la patria potestad sobre otro de sus hijos, diferente de quien está desheredando. 
No incluye como causal la limitación de la patria potestad; solamente su pérdida. Pero, aun invocando esta última, se requiere sentencia que condene a la perdida de la patria potestad.

\subsection{2. "Cuando les negaren los alimentos, sin motivo legítimo" (Código Civil Uruguayo. Ley 16.603 de 1994. 19 de octubre de 1994. Uruguay).}

Se trata de una causal que, además de ser motivo suficiente para desheredar a los ascendientes del testador, está incluida en el art. 900 ya analizado como excluyente del beneficio para aquel hijo o descendente que haya negado alimentos al testador.

Se trata de una causal que opera tanto para cuando los hijos son menores, como cuando son mayores, pero deben operar los requisitos previstos en la ley para el nacimiento de la obligación alimentaria (títulos para pedirlos, necesidades del beneficiario, y posibilidades de quien debe sufragarlos), de acuerdo con los arts. 122 del C.C.U y 46 del Código de la Niñez y de la Adolescencia (C.N.A.).

4.3.3. "Cuando el padre atentó contra la vida de la madre o ésta contra la de aquel y no hubo reconciliación entre los mismos" (Código Civil Uruguayo. Ley 16.603 de 1994. 19 de octubre de 1994. Uruguay).

A pesar de que el precepto se refiere a la reconciliación, en verdad parecería estar recogiendo el instituto del perdón o de la remisión. La posibilidad de desheredar se mantiene siempre que no haya reconciliación entre los padres. Por lo expuesto, desaparece la posibilidad de desheredar en caso de que se pruebe a través de cualquier medio dicha la reconciliación antes de que se otorgue el testamento que deshereda.

En caso de que se haya otorgado testamento y la reconciliación sobrevenga con posterioridad; la desheredación se mantendría hasta tanto no se revoque el testamento que incluye dicha disposición testamentaria. Por lo expuesto, se puede concluir que si bien se exige la reconciliación de los padres, quien realmente debe remitir la causal es el propio hijo-testador. (Howard, 2019)

\section{Prueba de las causales de desheredación}

El art. 898 del C.C.U señala que "La causa en que se funda la desheredación deberá ser alguna de las señaladas expresamente en la ley y probarse, además, por las personas a quienes interesare la desheredación, si no se hubiese probado judicialmente en vida del testador" (Código Civil Uruguayo. Ley 16.603 de 1994. 19 de octubre de 1994. Uruguay).

Se debe interpretar que la causa de desheredación, en algunos casos, puede estar plenamente probada en vida del testador. Sin embargo, otras veces, la probanza de la causal opera una vez ocurrido el deceso del testador.

No obstante, aún en esta última hipótesis, la causal debe ser probada de todos modos cuando el desheredado controvierta en vía judicial la privación de la legitima. Para 
que se descargue prueba de la misma por parte de quien se encuentra interesado en la desheredación, se requiere como presupuesto que el desheredado haya accionado contra dicha cláusula testamentaria. Si esto último no ocurre, nos encontraremos frente a un supuesto de aceptación tácita de la operatividad de la causal, y, por lo tanto, nada debería probarse acerca de ella (Howard, 2019).

Ahora bien, si la causal fue probada judicialmente en vida del testador, la pregunta que nos debemos plantear es si esa causal debe tenerse como plenamente probada a los efectos de la desheredación.

Si se entendiera que dicha causal, plenamente probada judicialmente y en vida del testador, alcanza a la desheredación, la persona interesada en que opere la desheredación no debería invocar ningún tipo de prueba al respecto; debiendo, el excluido de la sucesión, impugnar la cláusula testamentaria por la cual se decide desheredarlo.

Ahora, si se entendiera que la causal no debe tenerse plenamente probada a los efectos de la desheredación-. más allá de que la misma se haya probado judicialmente en vida del testador- el onus probandi se desplaza a quien interesa la desheredación.

Suponiendo que la causal, probada judicialmente en vida del testador, alcanzara a la desheredación, a mi criterio si abren dos interpretaciones:

Quienes entienden, por un lado, que el interesado en la misma no debería probarla, puesto que la ley condiciona la probanza de la causal por este último solo "si no se hubiese probado judicialmente en vida del testador".

Por otro lado, quienes entienden que, habiéndose probado en vida del testador, la misma de todos modos debe ser probada por quien le interesa la desheredación y a los efectos de esta última, tomando como argumento principal que la probanza se limita a las partes que intervienen en un juicio. Puede que la causal, aun probada judicialmente en vida del testador, no le sea oponible al desheredado por no haber sido parte del proceso judicial en que se probó.

El alcance de la cosa juzgada está limitado a aquellos que intervinieron en un juicio; si en este último se probó la causal de desheredación, no es un obstáculo para que se pruebe aún por el interesado en ella, siempre que el desheredado no haya sido parte de aquel juicio.

No es oponible el alcance de la cosa juzgada a terceros que no fueron parte del procedimiento y; más aún, la prueba diligenciada en ese procedimiento tampoco debe serle oponible al desheredado, en tanto la misma se diligenció sin su contralor por tratarse de un juicio del cual él no formaba parte. De allí que, si se adoptara esta última postura, el onus probandi continuaría sobre espaldas de quien interesa la desheredación.

Ahora bien, cuáles son las posibles acciones o defensas que tendría el afectado frente a la desheredación:

Por un lado, podría promover la acción de nulidad, en la medida en que la desheredación no haya cumplido con todos los requisitos de validez que exige el art. 897 del C.C.U. Debemos interpretar que se trata de requisitos de validez, siendo que la propia norma así lo indica cuando expresa "para que valga la desheredación se requiere.". Por 
lo tanto, si se omitieron algunos de los requisitos, la acción a impetrar es la de nulidad, siendo plenamente aplicable el art. 1560 inciso 1 del C.C.U: nulidad absoluta.

No obstante, si los requisitos de validez se han cumplido, pero el desheredado discrepa con la solución adoptada por el testador, al considerar que sus comportamientos están realmente alejados de las causales alegadas considerando que la causal invocada es inexistente o no se ha verificado, en este caso la acción a impetrar sería la de reforma de testamento, consagrada en los arts. 1006 y stes. del C.C.U.

Es importante diferenciar estos dos tipos de acciones que se encuentran en manos del afectado para accionar, puesto que ambas figuras divergen en cuanto a sus efectos. Si se opta por la acción de nulidad, rigen a su respecto todas las exigencias en cuanto a la carga probatoria prevista en el 139 del Código General del Proceso, (en adelante C.G.P.), puesto que quien alega un hecho, debe probarlo. Además, al tratarse de una nulidad absoluta es imprescriptible. Sin embargo, en el supuesto de que la acción a promover sea la de reforma de testamento, la hipótesis es diferente, ya que se encuentra sujeta a un plazo de prescripción de cuatro años contados desde el día en que el desheredado conoció el testamento del difunto; además de que la ley beneficia al afectado puesto que la carga probatoria recae sobre quien interese la desheredación, de acuerdo con el antes citado art. 898 del C.C.U.

Entonces, ¿quiénes son los interesados de la desheredación? No solamente se puede incluir a los herederos del testador, sino también a todos aquellos que se puedan ver afectados en caso de que la acción de reforma de testamento o la acción de nulidad triunfe. Es a los sujetos que interesa la desheredación sobre quienes recae la prueba de los hechos constitutivos de la causal alegada; si no cumplen con el deber de prueba que la propia ley les impone, van a sufrir los perjuicios que de ello se derive, es decir, la declaración de ineficacia de la desheredación.

\section{Nuestra normativa actual}

Tal como lo hemos adelantado, las causales de desheredación deben interpretarse taxativamente atento a su característica sancionatoria. Los principios de legalidad y de tipicidad afloran al momento de acceder a ellas, no pudiéndose aplicar analógicamente dada su naturaleza condenatoria.

Nadie puede ser sancionado por un comportamiento que al momento de su perpetración no se encontraba regulado por la ley como una causal de desheredación. Además, la conducta que desarrolla el legitimario debe ajustarse a los presupuestos detalladamente establecidos en la norma, no admitiéndose una extensión analógica del comportamiento cuando el mismo no se encuentra en su totalidad recogido por el cuerpo legal.

Ahora bien, dadas las características antedichas, se advierte que existen comportamientos incluso más graves que los que se encuentran previstos por la normativa, pero, al no encontrarse regulados, no podrían invocarse como una causal válida para la desheredación. 
Por lo expuesto y atento a las características que tiene la institución de las legítimas en los ordenamientos jurídicos actuales, la doctrina ha considerado de vital importancia reformar los sistemas jurídicos introduciendo las llamadas causas "abiertas" para desheredar. Las mismas son causas que, por su expresión legal, permiten un mayor margen de interpretación y en las que la libertad de testar del causante tiene un mayor protagonismo, como sucede, por ejemplo, con el comportamiento inmoral del legitimario (Howard, 2019).

\subsection{Abandono emocional}

Comportamientos tales como el abandono emocional del padre por parte del hijo no se encuentran taxativamente previstos en la norma; sin embargo, por su naturaleza nos cuestionamos si es posible su inclusión dentro la causal maltrato de obra recogida en el art. 900 nral 1 del C.C.U.

El abandono emocional se da en aquellas situaciones en las cuales el testador mayor, necesita de cuidados, atención y afecto de sus descendientes. La falta de interés, de comunicación, de cuidados, de afectos - independientemente de los aspectos materiales del cuidado de los adultos mayores-, son comportamientos que vulneran el componente ético y moral que debe tener las relaciones entre padres e hijos.

Según la Real Academia Española (en adelante, R.A.E), el abandono, en una de sus acepciones, se define como "dejar solo a alguien alejándose o dejando de cuidarlo". Desamparar a un ascendiente implica desasistirlo y eso es incompatible con los deberes que derivan de la relación jurídica paternofilial. Desde esta perspectiva se trata de determinar si el abandono emocional tiene encaje en la causa de maltrato de obra (Algaba Ros, 2015). Tal conducta, además de incluirse dentro de la hipótesis del maltrato de obra, consiste en un incumplimiento de las obligaciones que tienen los hijos respecto de sus ascendientes, en tanto que descuidar también se define como desatender las obligaciones.

El nuevo panorama social nos conduce a la necesidad de interpretar las normas conforme a la actual realidad social. El contexto social que vivimos actualmente pone de manifiesto que el abandono emocional de un mayor debe ser tenido presente en nuestra normativa, permitiendo a éste desheredar a sus descendientes cuando sea objeto del mismo. No tiene sentido que el ordenamiento no le permita privar de la legítima a aquellos sujetos que no han mantenido con el testador-abandonado ninguna relación familiar. Sería como obligar al testador a respetar unos lazos familiares que han quedado rotos, mientras que ninguna sanción recibe el legitimario que ha roto los propios lazos familiares. No se admite el hecho de que los padres deban dejar a sus hijos su legítima, aunque durante años hayan mantenido una postura de indiferencia, alejamiento y abandono emocional para con sus padres.

En una sentencia del Tribunal Supremo español, se señala que el "hecho de que las causas de desheredación sean de enumeración taxativa sin posibilidad de analogía, "no significa que la interpretación o valoración de la concreta causa, previamente admitida por la ley, deba ser expresada con un criterio rígido o sumamente restrictivo" (Tribunal Supremo 1 a , 3.6.2014 (RJ.3900)15). Señala la referida sentencia que las causas de desheredación deben ser objeto de una interpretación flexible conforme a la realidad social, al signo cultural y a los valores del momento en que se producen (Algaba Ros, 2015). 
Si bien el entorno social que actualmente vivimos exige una interpretación flexible de las diferentes causales a los efectos de abarcar comportamientos que, aun no recogidos expresamente, puedan invocarse como causal de desheredación atento a la voluntad del causante; se debe mencionar que la interpretación extensiva que se procure no debe llegar a la analogía. Se debe interpretar la norma de forma tal que el resultado de dicha interpretación sea acogido por la propia norma, atento a la realidad social que vivimos.

\subsection{El maltrato psicológico}

Junto con el maltrato de obra, también debe considerarse como una causa de la privación de las legítimas el maltrato psicológico que efectúan los hijos para con sus padres. La jurisprudencia en derecho comparado ha entendido que es conveniente que los sistemas se limiten a reconocer como motivos de desheredación un "maltrato" genérico, dejando así mayor libertad al juez para apreciar si efectivamente existe una infracción grave de los derechos y deberes familiares antes que atender a las causas específicas, tasadas y, probablemente, más severas, previstas por el legislador.

En particular, el Tribunal Supremo español parece inclinarse por la necesidad de permitir que el testador pueda privar de la legítima al descendiente que lo desampara en situación de necesidad o especial vulnerabilidad, que sería la máxima expresión de la infracción de un deber legal y/o moral hacía el progenitor, tal y como sucede en otros ordenamientos jurídicos que lo recogen (Arroyo Amayuelas y Farnós Amorós, 2015).

\subsection{La falta de trato familiar}

Se ha considerado de especial relevancia la falta de trato familiar; tomando en casos particulares mayor relevancia que un maltrato físico perpetrado por los hijos para con sus padres, o los insultos de los primeros para con los segundos.

Se ha entendido por parte del Tribunal Supremo español que siempre es grave y culposa la conducta de quien abandona en manos de terceros o en soledad a sus padres, máxime si estos enferman antes de morir y aunque ello no les coloque en una situación de necesidad material (Arroyo Amayuelas y Farnós Amorós, 2015).

Los intentos de desheredar al hijo en las hipótesis de rechazo de éste al contacto con el padre, generalmente como consecuencia de la separación de los progenitores, es una hipótesis que se ha ido admitiendo progresivamente en varias sentencias del Tribunal Supremo como motivo contundente para invocarlo como causa de desheredación.

A vía de ejemplo, en el Código Civil Cataluña, en su artículo 443-5, se supedita los derechos sucesorios ab intestato del hijo o hermano adoptado, en la herencia de su padre o hermano biológicos (en determinados tipos de adopción), al mantenimiento de "trato familiar" entre ellos.

No obstante, la privación de la legítima por falta de trato no puede identificarse directamente con la falta de convivencia. Se entiende que lo normal es que padres e hijos ya no convivan cuando nace el derecho a la legítima. No puede entenderse rota la relación, por muchas desavenencias que existan entre el testador y el legitimario, si estos conviven bajo el mismo techo; y tampoco podrá apreciarse ausencia de relación familiar cuando no convivan, pero el legitimario visite al causante, aunque solo sea de vez en cuando (Arroyo Amayuelas y Farnós Amorós, 2015). 


\section{Jurisprudencia}

\section{Desheredación del hijo por el padre}

Sentencia primera instancia: Juzgado Letrado de Primera Instancia en los Civil de $18^{\circ}$ Turno. “R. de C., J contra C., A.A. - Desheredación (F.A. N 85/969). Montevideo, 28 de octubre de 1969.

Sentencia segunda instancia: Tribunal de Apelaciones en los Civil de segundo turno. $\mathrm{N}^{\mathrm{o}}$ 296. Montevideo, 25 de noviembre de 1970.

\subsection{Hechos}

El causante, P.B.C, casado en terceras nupcias con J.R, con fecha 11 de mayo de 1962 otorgó testamento previendo en una de sus cláusulas la desheredación de su hijo A.A.C.G., habido de su primer matrimonio con A.G, por haber configurado causal del adulterio con su madrastra, P.C.D, esposa de segundas nupcias del causante. Este último instituyó única universal heredera a su última esposa de terceras nupcias, J.R de C.

Comparece el hijo del causante, A.A.C.G, solicitando se lo declare único y universal heredero, manifestando no haberse probado la causal de adulterio a su respecto, ya que la misma fue invocada en el juicio de divorcio entre P.B.C y P.C.D., en el cual él no tuvo ningún tipo de intervención. Frente a este hecho, la esposa del causante de terceras nupcias, J.R de C, acciona contra el primero invocando su calidad de única instituida universal heredera, incorporando como prueba de la causal el expediente relativo al divorcio por adulterio seguido por el causante y su esposa de segundas nupcias.

En primera instancia, resolución caratulada " $R$. de C,. J contra C.,A.A-Desheredación" se desestimó la demanda interpuesta por la parte actora, instituida universal heredera, la Sra. J.R, fundamentando que la desheredación solamente debe proceder cuando exista justa causa de desheredación, plenamente probada. De acuerdo al art. 898 del C.C.U, la causal de desheredación debe probarse por las personas a quienes interesase la desheredación, en el supuesto de que la misma no se haya probado judicialmente en vida del testador. La causal de adulterio invocada por las partes en el proceso de divorcio surge acreditada con el límite de la autoridad de la cosa juzgada, alcanzado únicamente a las partes intervinientes en el proceso de divorcio.

El tribunal entendió que la declaración de adulterio fue formulada en un contradictorio totalmente ajeno al heredero que se pretende excluir, puesto que este último respecto de aquel procedimiento es un tercero, no teniendo posibilidad de ninguna injerencia en aquel proceso, menos aún, en el diligenciamiento de la prueba producida en el mismo. La sentencia dictada en el marco del juicio de divorcio reviste el alcance de la autoridad de la cosa juzgada, no siendo oponible a A.A.C.G, pues no ha sido parte de dicho procedimiento, no pudiendo defenderse respecto de la conducta personal y agraviante que se le señala. Concluye que la causal no se ha probado en vida del testador, motivo suficiente para trasladar la carga de la prueba de la causal a J.R de C. 
En segunda instancia, comparece la parte actora, J.R de C, agraviándose de la resolución dictada en primera instancia, alegando que la prueba producida por el desheredado no fue suficientemente hábil para demostrar la inexistencia de la causal que se invoca a su respecto. El tribunal, por su parte, manifiesta que el adulterio, más allá de su trascendencia y gravedad, no se encuentra comprendido dentro de la causal prevista en el inciso 1 art. 900 invocado por la parte actora. En otras palabras, dicho comportamiento resulta excluido de la enumeración legal. Pero aun hipotéticamente admitiendo que la causa de desheredación es legal, entiende el tribunal que no resultó judicialmente probada en vida del testador por el alcance de la cosa juzgada, limitada a las partes el proceso de divorcio.

El precitado caso jurisprudencial resulta notoriamente interesante a los efectos de analizar las diferentes posiciones que se podrían haber adoptado para dar resolución al caso, independientemente de los fallos efectivamente dictados en ambas instancias por los tribunales intervinientes.

Así las cosas, podemos preguntaros lo siguiente: 1) ¿qué argumentos se podrían haber manejado en defensa de la protección de los derechos del cónyuge en terceras nupcias, instituido testamentariamente, del fallecido. 2) ¿cuáles podrían haber sido los argumentos invocados en defensa de la protección de los derechos del hijo desheredado.?

\subsection{Argumentos se podrian haber manejado en defensa de la protección de los derechos del cónyuge en terceras nupcias, instituido testamentariamente.}

Le desheredación, teniendo su origen en la voluntad del testador, siempre que cumpla con los requisitos legalmente previstos, es idónea para generar la exclusión sucesoria de los legitimarios.

Aplicable a la situación en estudio es la causal prevista en el art. 900 numeral 1, ya que haber maltratado de obra o haber injuriado gravemente la palabra del padre es motivo suficiente para afectar el beneficio que se tiene como legitimario. Jurisprudencialmente se ha identificado el maltrato de obra no solamente como maltratos corporales, o lesiones físicas; se han visto alcanzados los daños psicológicos. Las ofensas y agravios psicológicos generan un sufrimiento y deterioro a la salud mental del causante de gran significación. La injuria, por su parte, debe entendérsela como daño o perjuicio causado al padre. Lo dicho por cuanto no debemos circunscribir los maltratos de obra a maltratos físicos, ni las injurias graves de palabra a maltratos psicológicos.

Si bien es admitido que las causales de desheredación son taxativas, eso no obsta una interpretación flexible y extensiva de las mismas, conforme a la realidad social del momento que se vive. Dicha causal es corolario del incumplimiento de ciertos deberes que tienen los hijos respecto de sus padres, como el de honrarlos y respetarlos (art.256 CCU). Así, en doctrina, se ha considerado este articulo determinante en tal contexto, puesto que: "se trata de una máxima, a la vez moral y religiosa. Se consagra un deber moral, sin limites de tiempo y espacio" (Cestau, 1999, p. 34).

Trascendente es recordar que los vínculos de familia son los que principalmente se tienen en cuenta cuando un sujeto no ha testado, o aun cuando lo ha hecho. Si la persona que es llamada a heredar, como legitimaria, comete ciertos actos, notoriamente ofensivos 
y perjudiciales para la persona que ha de suceder, nada impide que éste último lo prive de su legítima a través del instituto en estudio, puesto que contradice principios de moralidad, el hecho de favorecer a quien, por su conducta manifiestamente reprobable, no es digno ni merecedor de recibir tal beneficio.

La disposición testamentaria, por la cual se instituye universal heredera a la cónyuge en terceras nupcias, responde a un acto de última voluntad del causante. Este hecho no puede dejarse de lado; a pesar de tener disposiciones civiles notoriamente rígidas se debe hacer un esfuerzo por efectuar una interpretación flexible de la normativa que nos gobierna.

Mas allá de las normas procesales, no debemos olvidar que el adulterio fue motivo suficiente para efectuar la disolución del matrimonio entre el causante y su cónyuge de segundas nupcias. Definido por la R.A.E. como "ayuntamiento carnal voluntario entre persona casada y otra de distinto sexo que no sea su cónyuge" nos lleva a concluir que la prueba directa del mismo es prácticamente imposible, dando cabida a la prueba por presunciones. Tomando dicho punto en consideración, la probanza de la causal escapa de las posibilidades de la cónyuge en terceras nupcias, instituida universal heredera. Aclarando el asunto: ¿existe prueba, para el adulterio, más contundente que la considerada en el expediente de divorcio?, ¿puede, la instituida universal heredera, probar dicho adulterio? Estas son las preguntas que nos tenemos que hacer. La respuesta negativa no es sorprendente, y la estimo adecuada; puesto que, si es dificultosa su probanza para las partes en proceso de divorcio, más arduo lo seria para la instituida universal heredera hacerlo en éste.

\subsection{Argumentos invocados en defensa de la protección de los derechos del hijo desheredado}

Que desheredación es instituto que afecta las legítimas -parte de bienes que la ley asigna a cierta clase de herederos de manera independiente a la voluntad del testador. Solamente se los podría privar de tal derecho siempre y cuando exista una causa legal y probada de_desheredación.

Conforme a los arts. 889 y 900 del CCU, las causales intervinientes son taxativas. No podrán alegarse otras que no fueran las que se encuentran taxativamente previstas.

El legislador ha previsto de manera taxativa las causales de desheredación, atento a la nota sancionatoria que tiene la figura, la cual debe adherirse a los principios de legalidad y tipicidad propio de este tipo de sanciones.

Tal como resulta aplicable en la desheredación; el instituto de la indignidad como una forma de exclusión sucesoria también se sostiene la taxatividad de las causales, su característica de numerus clausus. Perfectamente aplicable al instituto en estudio es la opinión sustentada por la Suprema Corte de Justicia en el fragmento de la siguiente sentencia:

Como se advierte, la tesis general de los recurrentes, en el sentido de una interpretación extensiva de las causales de indignidad, aplicables a toda conducta moralmente recriminable del sucesor, carece de todo apoyo en los textos legales, en sus antecedentes y en su interpretación doctrinaria y no se compadece con la naturaleza de pena privada de aquéllas. (Sentencia Suprema Corte de Justicia, $N^{\circ} 310 / 2014$ ) 
Siendo causales taxativamente previstas por la ley que constituyen la fuente de una grave pena civil a efectos de que sea aplicable la sanción se requiere que se produzca lo que la doctrina penal denomina "la adecuación típica" entre la conducta realizada por heredero o legatario, y la descripta por la ley (Carozzi, 2010, p 131).

A través de la taxatividad se pretende no afectar el principio de intangibilidad de las legítimas, plenamente de recibo en nuestro ordenamiento jurídico.

Si bien existe un reconocimiento de la autonomía privada para toda persona consistente en otorgar testamento, cuando se priva a los herederos forzosos de los derechos que les corresponden en su calidad de tales, la adopción de la medida solo es operable cuando se encuentra presente una de las causales aptas para ello; pero incluso el legislador ha otorgado una garantía más para el desheredado, en virtud de que si este niega la existencia de hechos que llevaron a la desheredación , la ley impone, a quien contradiga esa afirmación, la carga de la prueba (Howard, 2019, p 556).

Así, en una sentencia del Tribunal de Apelaciones de Familia $1^{\mathrm{o}}$ T. se entendió lo siguiente:

En consecuencia, corresponde amparar la demanda en cuanto se vulnera la legítima de la accionante -legitima rigorosa (sin acrecimientos) y/o en su caso la legítima efectiva propia (acrecimientos de la porción legitimaria dispuestos por los numerales 893 num. 1 y 2 CC) ya que como expresa la autora citada "la intangibilidad es una nota esencial de la legítima rigorosa en sentido estricto (esto es la legítima sin acrecimiento alguno), así como la de la legitima efectiva propia (la que se ve acrecida con cuotas que vienen de la porción legitimaria) (Sentencia Tribunal de Apelaciones de Familia $1^{\circ}$ T. nro. 396/2012).

Aun pretendiendo invocar la causal prevista en el artículo 900 numeral 1 del C.C.U; haber maltratado de obra o haber injuriado gravemente de palabra al padre, o ascendiente que le deshereda, a contrario sensu de los fundamentos que sostuvimos en el apartado anterior, podría aducirse que las casales no deben ser objeto de una interpretación extensiva o analógica, atendiendo al perjuicio que ello causa al legitimario.

La ley se limita a establecer la causal, no determinando el alcance de los términos contenidos en ella. No se encuentran ni descritos ni definidos por el Código Civil tales extremos; si la ley no lo distingue, el intérprete tampoco debe hacerlo.

Notoriamente esta última fue la postura seguida por los tribunales en ambas instancias en el caso comentado, apegándose a un criterio literal de la normativa, entendiendo que la causal de adulterio no es una causal legal de las enumeradas en el artículo, por no encontrarse amparada en ninguna de las hipótesis.

En la hipotética situación de que la conducta del legitimario hubiere ingresado en alguna de las causales previstas legalmente, nos queda un paso más por revolver: la prueba de la desheredación. Mas allá de que la desheredación sea válida, en virtud del artículo 897 del C.C.U, la causal tiene que relacionarse directamente con el heredero, a quien perjudica, atribuyéndosele una conducta personal y propia agraviante y, si bien se invocó como causal de disolución del matrimonio del causante con su cónyuge en 
segundas nupcias, dicha prueba diligenciada en ese proceso no es oponible al tercero (legitimario) habida cuenta del alcance de la cosa juzgada, siempre limitada a quienes fueron parte del proceso.

Siguiendo la línea de pensamiento del tribunal, la última alternativa en materia de probanza la tiene la instituida heredera quien, como interesada, no desarrollo actividad probatoria suficientemente energética para que opere la exclusión.

\section{Conclusiones}

La desheredación se trata de una hipótesis de exclusión sucesoria recogida en el Código Civil Uruguayo; su procedencia será válida siempre que se reúnan los requisitos que la ley prescribe en el art. 897.

Atento a la característica sancionatoria que padece, y las eventuales consecuencias que apareja el hecho de que un sujeto sea desheredado, la interpretación de las diferentes causales recogidas en la norma debe ser de interpretación estricta, apegada al principio de legalidad y tipicidad; por ser causales que no deben ser extensibles analógicamente.

La pérdida de la legitimas es la sanción que nuestra norma recoge para aquel legitimario que haya incurrido en algunas de las conductas prescriptas.

Sin perjuicio de lo antes dicho, y a la luz del contexto actual que se vive, se comprende que la rigidez en las causales previstas por el Código Civil ha dejado por fuera conductas que son notoriamente reprobables, como la reflejada en el caso jurisprudencial comentado.

La falta de ductilidad y flexibilidad de la normativa se torna evidente, y necesario resulta replantearnos una reforma del sistema, e introducir cláusulas "abiertas" para desheredar o declarar la indignidad. Consecuentemente, se le garantizaría mayor protagonismo a la libertad de testar del causante, puesto que la amplitud en las causales respondería y se adecuaría a los intereses del mismo, evitando conceder beneficios a quien no es digno ni merecedor de percibirlos por los comportamientos en los que ha incurrido.

\section{Referencias Bibliográficas}

Algaba Ros, S. (2015), Maltrato de obra y abandono emocional como causa de desheredación, Rev.InDret, Revista para el Análisis del Derecho 2/2015, pp 9-11. Recuperado de www.indret.com, [fecha de obtención: 29 de abril de 2021].

Arroyo Amayuelas, E. y Farnós Amorós, E.(2015) Entre el testador abandonado y el legitimario desheredado ¿A quién prefieren los tribunales?, Rev.InDret, Revista para el Análisis del Derecho 2/2015, pp 8-17. Recuperado de www.indret.com. [ fecha de obtención: 29 de abril de 2021]

Carozzi, E. (2010) Manual de Derecho Sucesorio, T. 1, Montevideo: Fundación de Cultura Universitaria.

Cestau, S. D. (1999) Personas (Vol. 3), Montevideo: Fundacion de Cultura Universitaria. 
Código Civil Uruguayo. Ley 16.603 de 1994. 19 de octubre de 1994. Uruguay.

Howard, W. (2016) Alimentos, Montevideo: Fundación de Cultura Universitaria.

Howard, W. (2019) Derecho de las Sucesiones, T. I, Montevideo: Fundación de Cultura Universitaria.

Howard, W. (2020) Derecho de las Sucesiones, T. II, Montevideo: Fundación de Cultura Universitaria.

Rivero De Arhancet, M. (2001) Lecciones de Derecho Sucesorio, Montevideo: Fundación de Cultura Universitaria. 